\title{
A CRYSTALLINE DIFRUCTOSE ANHYDRIDE FROM HYDROLYZED INULIN
}

\author{
By Richard F. Jackson and Sylvia M. Goergen
}

ABSTRACT

The polysaccharide, inulin, has previously been shown to consist solely of fructose residues. Even if highly purified by recrystallization, however, inulin yielded upon hydrolysis with aqueous acids fructose solutions of but 92 per cent purity, regardless of the nature of the acid or the temperature at which the hydrolysis was carried out. The 8 per eent residue consisted of about 3 per cent aldose and 5 per cent nonreducing substance. The latter was isolated by removal of fructose by lime and fermentation of reducing sugars by yeast. The nonreducing residue showed a $[\alpha]_{D}^{20}=+55$ and yielded fructose by hydrolysis. The substance proved to be twenty-five times as resistant to hydrolysis as the remainder of the inulin molecule. Acetylation produced an oil from which 30 per cent crystallized in the form of prismatic needles. The latter after puriiication showed $\mathrm{a}[\alpha]_{D}^{20}=+0.54$ in chloroform and contained but six acetyl groups. No modification of procedure produced a more highly substituted compound. Analysis and molecular-weight determination showed that the compound was the hexa-acetate of a disaccharide.

The hexa-acetate was deacetylated and the parent sugar obtained in crystalline form. It crystallized in minute plates from absolute alcohol and showed $[\alpha]_{D}^{20}=+27$ in water. Its formula, $\mathrm{C}_{12} \mathrm{H}_{20} \mathrm{O}_{10}$, obtained from accumulated evidence, indicated that the substance was a difructose anhydride.

The mother liquors from the crystalline hexa-acetate showed a $[\alpha]_{D}^{20}=+31$ and a molecular weight corresponding to a disaccharide. There are, therefore, two or more isomeric disaccharides in the inulin residue.

Inasmuch as there is apparently a group of difructoses awaiting isolation, the sugar of $[\alpha]_{D}^{20}=+27$ is designated difructose anhydride $\mathrm{I}$.

\section{CONTENTS}

I. Introductory _...

II. Purification and hydrolysis of inulin ........ 28

III. Isolation of dextrorotatory constituent.

IV. Acetylation of inulin residue....... 30

V. Difructose anhydride.

VI. Experimental_._-_._. 32

1. Purification of inulin _. 32

2. Hydrolysis of inulin

3. Analysis of hydrolyzed inulin solutions _............... 33

4. Isolation of nonreducing residue from hydrolyzed inulin.---- 34

5. Hydrolysis of inulin residue....... 34

6. Difructose anhydride hexa-acetate.

7. Difructose anhydride I_._.

8. Hydrolysis of difructose anhydride I

9. Effect of $\mathrm{H}_{2} \mathrm{SO}_{4}$ on pure fructose

VII. Summary 


\section{INTRODUCTORY}

The polysaccharide, inulin, was shown by Irvine and Steele ${ }^{1}$ to consist solely of anhydro- $\gamma$-fructose residues. C. Tanret ${ }^{2}$ had previously found that inulin in aqueous solution yielded upon hydrolysis with dilute acid sugar mixtures of specific rotation -81.3 , very far short of the rotatory power of pure fructose. He concluded that the products of hydrolysis consisted of 12 parts fructose and 1 part glucose. Jackson, Silsbee, and Proffitt ${ }^{3}$ studied the hydrolysis carefully and were able to obtain solutions of but 91 per cent purity ${ }^{4}$ with respect to fructose. The anomaly exists, therefore, that, while inulin consists solely of fructose residues, hydrolysis fails signally to yield pure fructose solutions. The present paper is a study of the hydrolysis of inulin in aqueous solution and of the nature of the carbohydrates other than fructose produced by the hydrolysis.

\section{PURIFICATION AND HYDROLYSIS OF INULIN}

Since the possiblity existed that a persistent impurity, such as a hemicellulose, was responsible for the low purity of the hydrolyzed inulin, the purification was studied in detail. The inulin was repeatedly recrystallized from aqueous solution, and after each operation a portion was hydrolyzed and analyzed. It became evident that one recrystallization of the crude material produced a product indistinguishable by the analyses from one recrystallized repeatedly. Attention was then directed to the accumulated mother liquors, which were evaporated and fractionally crystallized. All products yielded solutions of about 92 per cent purity after hydrolysis.

The purity of the hydrolyzed inulin solution was found to be practically independent of the method of hydrolysis. Whether hydrolyzed with sulphuric acid at room temperature or with tartaric acid at boiling temperature or at intermediate temperatures and acidities, the purity was approximately the same, provided the hydrolysis was continued to apparent completion as indicated by the constancy of rotation.

In Table 1 are assembled the analytical data accumulated during the studies of purification and hydrolysis. While the variations are somewhat greater than the analytical uncertainties, the averaged values probably represent closely the composition of hydrolyzed inulin. The percentages are based upon 100 per cent dry substance, determined densimetrically in the hydrolyzed solution and, except in experiment No. 2, after removal of the hydrolytic agent. Experi-

1 J. Chem. Soc., 117, p. 1481; 1920.

2 Bull. Soc. Chim., 3d series, 9, p. 227; 1893.

3 B. S. Sci. Paper No. 519, 20, p. 604; 1926.

"The term "purity" is employed in the present paper in the quantitative sense customary in sugar analysis. It is the quotient of the amount of fructose divided by the total dissolved solids and is there. fore independent of concentration. 
ment No. 2 shows a somewhat lower purity than the others, owing to the partial destruction of fructose at the high temperature.

It will be observed that of the total carbohydrate but 91.8 per cent is fructose, that 94.8 per cent consists of reducing sugar estimated as fructose, and that there remains a nonreducing residue of 5.2 per cent. This residue is the main topic of the present paper. The nature of the 3 per cent nonfructose reducing sugar is still undetermined but will occupy our attention in a future investigation. That it is apparently an aldose sugar is indicated by its oxidizability by iodine.

TABLE 1.-Summary of hydrolysis experiments

\begin{tabular}{|c|c|c|c|c|c|c|c|c|c|}
\hline Experiment No. & $\begin{array}{l}\text { Fruc- } \\
\text { tose }\end{array}$ & $\begin{array}{l}\text { Total } \\
\text { rcduc- } \\
\text { ing } \\
\text { sugar }\end{array}$ & $\begin{array}{c}\text { Aldose } \\
\text { by } \\
\text { iodine }\end{array}$ & $\begin{array}{c}\text { Reduc- } \\
\text { ing } \\
\text { sugar } \\
\text { minus } \\
\text { fructosc }\end{array}$ & $\begin{array}{c}\text { Ratio } \\
\text { Fructose } \\
\begin{array}{c}\text { Reducing } \\
\text { sugar }\end{array}\end{array}$ & $\begin{array}{c}\text { Tem- } \\
\text { pera- } \\
\text { turc of } \\
\text { hydrol- } \\
\text { ysis }\end{array}$ & $\begin{array}{l}\text { Time of } \\
\text { hydrol- } \\
\text { ysis }\end{array}$ & $\begin{array}{c}\text { Nor- } \\
\text { mality } \\
\text { of } \\
\mathrm{H}_{2} \mathrm{SO}_{4}\end{array}$ & $\begin{array}{c}\text { Ap- } \\
\text { proxi- } \\
\text { mate } \\
\text { concen- } \\
\text { tration } \\
\text { of } \\
\text { inulin }\end{array}$ \\
\hline $\begin{array}{l}11 \\
2 \\
3 \\
3 \\
4 \ldots \\
4\end{array}$ & \begin{tabular}{|c|} 
Per cent \\
92.80 \\
90.21 \\
92.15 \\
90.76
\end{tabular} & \begin{tabular}{|c|} 
Per cent \\
94.87 \\
92.36 \\
94.84 \\
95.09
\end{tabular} & \begin{tabular}{|c|}
$P c r$ cent \\
1.80 \\
2.41 \\
1.82 \\
1.80
\end{tabular} & $\begin{array}{r}\text { Per cent } \\
2.07 \\
2.15 \\
2.69 \\
4.33\end{array}$ & $\begin{array}{r}0.978 \\
.977 \\
.972 \\
.955\end{array}$ & $\begin{array}{r}{ }^{\circ} \mathrm{C} . \\
48.6 \\
100.0 \\
48.6 \\
48.6\end{array}$ & $\begin{array}{c}\text { Hours } \\
3.08 \\
2.5 \\
6.0 \\
8.2\end{array}$ & $\begin{array}{l}N \\
0.1224 \\
.005 \\
.0729 \\
.070\end{array}$ & $\begin{array}{r}\text { Per cent } \\
13.2 \\
13.5 \\
13.9 \\
12.0\end{array}$ \\
\hline $\begin{array}{l}5 \\
7 \mathrm{a} \\
7 \mathrm{~h} \\
\mathrm{n}\end{array}$ & $\begin{array}{l}92.30 \\
91.70 \\
92.32 \\
92.53\end{array}$ & $\begin{array}{l}96.04 \\
95.57 \\
94.84 \\
94.96\end{array}$ & $\begin{array}{l}1.77 \\
2.38 \\
2.23 \\
2.23\end{array}$ & $\begin{array}{l}3.74 \\
3.87 \\
2.52 \\
2.43\end{array}$ & $\begin{array}{l}.961 \\
.960 \\
.973 \\
.974\end{array}$ & $\begin{array}{r}20-30 \\
20-60 \\
60.4 \\
60.4\end{array}$ & $\begin{array}{r}{ }^{3} 13 \\
{ }^{3} 6 \\
2.3 \\
3.2\end{array}$ & $\begin{array}{l}.15 \\
.13 \\
.08 \\
.08\end{array}$ & $\begin{array}{l}13.7 \\
14.9 \\
16.7 \\
16.7\end{array}$ \\
\hline A verage. & 91.85 & 94.82 & 2. 06 & 2.98 & .969 & & & & \\
\hline
\end{tabular}

1 The method of preparation of the individual samples of inulin is described in the experimental part of this article.

2 Tartario acid normality with reference to first hydrogen. Arsem. United States Patent No. 1616169; Feh. 1, 1927.

${ }^{3}$ Days.

\section{ISOLATION OF DEXTROROTATORY CONSTITUENT}

From the hydrolyzed sirup the fructose was removed very nearly quantitatively by precipitation as calcium fructosate, and the filtrate after fermentation by yeast was found to be free from reducing sugars.

The substances in this solution were found to have a specific rotation of about +55 . Although contaminated by impurities, a molecular-weight determination by the freezing-point method yielded the value 253, which suggested that the substance was mainly a disaccharide.

This material was extremely resistant to hydrolysis, but upon acidification to $0.4 \mathrm{~N}$ with $\mathrm{H}_{2} \mathrm{SO}_{4}$ partial hydrolysis was effected at boiling temperature. The dextrorotatory solution upon hydrolysis became strongly levorotatory. Careful analysis showed that the sole product of hydrolysis was fructose. 


\section{ACETYLATION OF INULIN RESIDUE}

From the dextrorotatory sirup no crystalline material could be obtained, but upon acetylation in the usual manner a portion, about 30 per cent, of the reaction mixture crystallized slowly in the form of prismatic needles. (Fig. 1.) This crystalline acetate was found to have a very low rotatory power and to contain but six acetyl groups. Consequently, in an effort to produce a more highly substituted compound, the acetylation of the original sirup was carried out repeatedly in the presence of the alternative catalysts, pyridine, zinc chloride, or sodium acetate, all of which catalyzed the reaction equally well. Polariscopic observation of the reaction mixture showed that, regardless of the nature of the catalyst, acetylation increased the rotatory power of the solution by about 10 per cent, and yet the same low rotating hexa-acetate in approximately the same yield was always recovered in crystalline form. The crystalline acetate itself was reacetylated but was recovered in unaltered form. It was, therefore, concluded that the original disaccharide contained but six hydroxyls and that the crystalline compound was the hexa-acetate of the disaccharide $\mathrm{C}_{12} \mathrm{H}_{20} \mathrm{O}_{10}$. This conclusion was corroborated by a molecular-weight determination and by a combustion analysis.

The hexa-acetate recrystallized to a pure state showed a $[\alpha]_{D}^{20}=+0.54$ in chloroform. It has been indicated above that the reaction mixture at the completion of the acetylation possessed a high rotatory power, whereas the only acetate recovered was obtained in low yield and had a very low rotatory power. Furthermore, the mother liquors showed a specific rotation of +31 and a molecular weight of 573 , the latter corresponding exactly to the hexa-acetate of a difructose anhydride. It is therefore evident that there were two or more acetates in the acetylation mixture, only one of which has been recovered in crystalline form. It will be shown below that this isomerism is not due to different modes of acetylation but is due to the presence of two or more different disaccharides in the original inulin residue.

\section{DIFRUCTOSE ANHYDRIDE}

The purified hexa-acetate was deacetylated by treatment with $\mathrm{Ba}(\mathrm{OH})_{2}$ and the parent sugar obtained in crystalline form. The sugar crystallized in minute plates usually too small to permit a study of their form. When grown under favorable conditions they were seen to consist of rectangular plates (fig. 2), infrequently having one corner cut off at an angle of $45^{\circ}$. These plates were extremely thin and, if allowed to separate from a still solution, coalesced to form hard laminated clusters approximately spherical in shape.

The purified sugar exhibited an $[\alpha]_{D}^{20}=+27$ in water. The substances in the original crude-inulin residue, as we have indicated above, showed a specific rotation of +55 . It is now evident that the latter 
B. S. Journal of Research, RP79

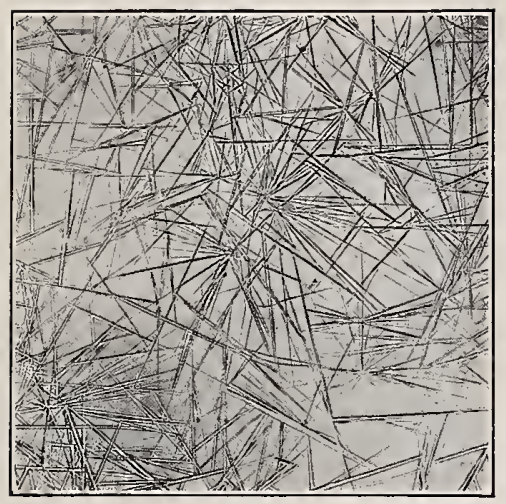

Figure 1.-Difructose anhydride I hexaacetate

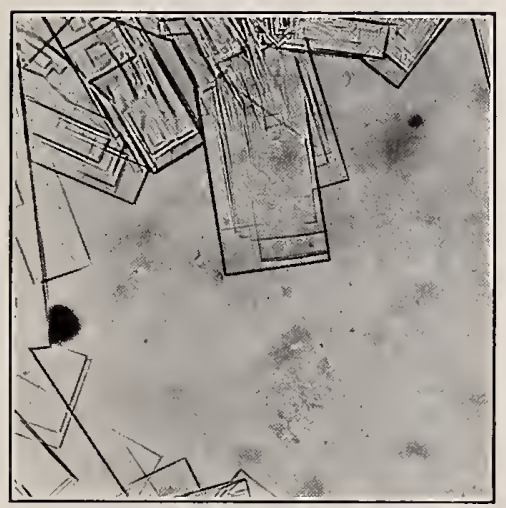

Figure 2.-Difructose anhydride I 
value is merely the average rotatory power of at least two disaccharides and the one or ones which have not been isolated must have high rotations and yield acetates of high rotation.

The difructose in aqueous solution like the original crude mixture showed great resistance to hydrolysis. In sulphuric acid solution of $\mathrm{pH}=0.965, \mathrm{C}_{\mathrm{H}+}=0.109$, it hydrolyzed at $100^{\circ} \mathrm{C}$. with a velocity constant of about 0.009 . In the work previously cited Jackson, Silsbee, and Proffitt found that inulin was hydrolyzed by $0.01 \mathrm{~N} \mathrm{HCl}$ with a velocity constant of 0.020 . The new difructose is therefore about twenty-five times as stable as the remainder of the inulin molecule, or about three hundred and twenty-five times as stable as cane sugar. An analysis showed that fructose was the sole product of the hydrolysis.

Previous work on the acetate had shown that the disaccharide was composed of two fructose residues condensed with a loss of two molecules of water. A combustion analysis of the sugar now proved definitely the formula $\mathrm{C}_{12} \mathrm{H}_{20} \mathrm{O}_{10}$. It is therefore a difructose anhydride.

Inasmuch as there is apparently a group of difructoses awaiting isolation, we suggest the designation Difructose Anhydride I for the sugar $[\alpha]_{D}^{20}=+27$. It is our purpose to ascertain the structural formula of this sugar in continuation of the present work.

Evidence has been presented in recent literature ${ }^{5}$ that inulin is constructed of difructose units either by association of difructose anhydride or by polymerization on classical principles of valence. The difructose anhydrides which we have described in the present paper can not serve for such units, for they are sharply distinct from the remainder of the inulin molecule in respect of their great resistance to hydrolysis.

The origin of these disaccharides is at present undetermined. Experiment showed that ordinary crystalline fructose is not condensed to difructose under the conditions of acidity and temperature which are suitable for the hydrolysis of inulin. The possibility that $\gamma$-fructose is condensed is also eliminated, for Jackson and Gillis ${ }^{6}$ have shown that invert sugar produced from cane sugar by acid hydrolysis possesses a rotatory power equal to that of invert sugar produced by enzyme hydrolysis if corrected for the influence of the acid on the rotation. The rotation of invert sugar by enzyme hydrolysis has been shown by Zerban ${ }^{7}$ to be exactly equal to the algebraic sum of the rotations of pure glucose and ordinary fructose.

The hypothesis that the difructoses were originally integral parts of the inulin molecule and on account of their high stability survived the hydrolysis was abandoned by the authors because as a logical

\footnotetext{
5 For example, Bergmann and Knehe, Ann., 449, p. 302; 1926; Schlubach and Elsner, Ber., 61, p. 2358; 1928; Haworth and Learner, J. Chem. Soc., p. 621; 1928.

B B. S. Sci. Paper No. 375, 16, p. 167; 1920.

7 J. Am. Chem. Soc., 47, p. 1104; 1925.
} $53811^{\circ}-20-3$ 
conclusion the inulin molecule would necessarily contain 40,80 , or 120 fructose residues if the 5 per cent of unhydrolyzed residue consisted of 1,2 , or 3 isomers, respectively.

It seems more probable that inulin, even when purified by many recrystallizations, may still consist of a number of closely related polysaccharides, some of which may contain the resistant difructose units and others aldose residues. Such a lack of homogeneity would account for the variable specific rotation which has been frequently observed and for the lack of precise agreement between the samples whose analyses are recorded in Table 1 of the present paper.

A remaining possibility is that the difructose anhydrides are formed by condensation of difructoses which may be intermediate products of the hydrolysis of inulin.

\section{EXPERIMENTAL}

\section{PURIFICATION OF INULIN}

The expressed juice from dahlias was treated with kieselguhr and filtered while hot. The filtrate was allowed to stand either at room temperature or at $0^{\circ} \mathrm{C}$. until the crystallization of inulin was complete. The separated inulin was collected on a filter and thoroughly washed. It was then redissolved in sufficient water to form an 18 to 20 per cent solution, treated with carbon if necessary, and recrystallized one or more times. In some instances the inulin was air-dried in order to preserve it for future experiments. On drying, the inulin shriveled and broke into hornlike fragments of a brownish-gray color. Before recrystallization or hydrolysis the dried inulin was suspended in water and kept in agitation for several hours. Under these conditions it formed a smooth paste free from lumps and indistinguishable from the undried material. No satisfactory criterion of purity was discovered. The specific rotations of samples which were deemed pure ranged from -38 to -40 , in agreement with previous investigations.

The inulin samples upon which the data are recorded in Table 1 were prepared as follows: Nos. 1 and 2, crude inulin was once recrystallized; No. 3, twice recrystallized; No. 4, four times recrystallized; No. 5, the combined mother liquors from samples 1 to 4 were evaporated and recrystallized, and the resulting crystals recrystallized; No. 6, mother liquors from No. 5 precipitated by alcohol and crystals recrystallized from water; No. 7 , a portion of No. 6 recrystallized from water.

\section{HYDROLYSIS OF INULIN}

A suspension containing from 12 to 17 per cent of inulin was agitated cold until free from lumps. It was then hydrolyzed under the variable specifications described in Table 1 . In every instance the course of the reaction was followed by polariscopic observation of 
samples taken at appropriate time intervals, and the reaction was considered complete when the rotation became constant. In some cases, as, for example, experiment No. 6, the inulin crystallized during hydrolysis. This made it necessary to heat the solution in order to redissolve the inulin, but it was at once cooled when this was accomplished. In one instance the sample was hydrolyzed until the reaction was apparently complete, and a portion, $7 \mathrm{a}$, was analyzed. The remainder, $7 \mathrm{~b}$, was heated for an additional hour before analysis. Both samples showed the same properties within the limits of analytical precision.

\section{ANALYSIS OF HYDROLYZED INULIN SOLUTIONS}

The cooled solution was titrated to exact neutrality with a barium hydroxide solution and the barium sulphate removed by filtration. The density of the filtrate was determined to 5 decimals at $20.00^{\circ} \mathrm{C}$. During the progress of the investigation a parallel research was conducted on the density of pure fructose solutions with the same degree of precision. This density table, which will be published in a later article, enabled us to determine with confidence the dry substance in the hydrolyzed inulin solutions. This procedure involved the assumption that the density of the unknown constituents was the same as that of fructose, but the deviations were for the present purpose unimportant. Total reducing sugars were determined by triplicate titrations by the method of Lane and Eynon, ${ }^{8}$ control solutions of known concentration being titrated simultaneously.

Fructose was determined by its reducing action on copper carbonate at $49^{\circ}$ C. according to a modification of the method proposed by Biourge ${ }^{9}$ and Nyns. ${ }^{10}$ The authors have examined this method in detail and have found it reliable, especially if fructose is the predominating substance present.

A portion of the hydrolyzed solution was tested for aldose sugars by iodine in the presence of sodium carbonate. ${ }^{11}$ Although a blank analysis was made with pure fructose of the same concentration, the results are probably of little more than qualitative value. Nevertheless, the excess of total reducing sugar over the fructose and the invariably positive test with iodine indicates the presence of approximately 3 per cent of an aldose sugar in the hydrolyzed inulin.

J. Soc. Chem. Ind., 42, p. 32; 1923.

- Bull. Assoc. Ecole de Brasserie (Louvain); January, 1898.

10 Ibid., January, 1925. C. A., 19, p. 1236; 1925.

" Cajori, J. Biol. Chem., 54, p. 622; 1922. 


\section{ISOLATION OF NONREDUCING RESIDUE FROM HYDROLYZED INULIN}

From the hydrolyzed solution the fructose was removed as the calcium fructosate in the manner described by Jackson, Silsbee, and Proffitt. ${ }^{12}$ The filtrate was caused to drain into a solution of oxalic acid in order to avoid the alkaline decomposition of the reaucing sugars. It was then adjusted to neutrality with lime and filtered. The filtrate was evaporated to about 15 per cent solids, and residual reducing sugars were removed by fermentation with yeast. The resulting solution was clarified with carbon and evaporated nearly to dryness. Alcohol was added to precipitate yeast products. For analysis, a sample of this solution was evaporated under diminished pressure with addition of water to displace alcohol.

Rotation. $[\alpha]_{D}^{20}$ in water $=+55$ (12.68 in $100 \mathrm{ml}$, calculated from $d_{4}^{20}=1.0474, \alpha=+40.68$, saccharimeter, $2 \mathrm{dm}$ tube). Mol. wt. Subs., 12.68: water, $92.06 ; \Delta T, 1.061$. Mol. wt., 253.

\section{HYDROLYSIS OF INULIN RESIDUE}

A $25 \mathrm{ml}$ portion of the residue in a $50 \mathrm{ml}$ thin-walled flask was made $0.40 \mathrm{~N}$ with $\mathrm{H}_{2} \mathrm{SO}_{4}$, plunged into boiling water, and vigorously agitated for 8 minutes. It was then cooled rapidly and polarized and again heated in boiling water for 15 minutes. Its rotation was initially +24.44 ; after 8 minutes, +5.42 ; and after 23 minutes, -19.32 . The solution was by this time too discolored for further polariscopic observation and was consequently analyzed to determine the products of hydrolysis. The following results are expressed in grams per $100 \mathrm{ml}$. Total reducing sugar, $5.49 \mathrm{~g}$; fructose by Nyn's method, $5.58 \mathrm{~g}$; fructose by temperature coefficient of polarization, $5.24 \mathrm{~g}$; fructose by direct polarization, $5.21 \mathrm{~g}$. The latter was calculated by subtracting from the observed polarization the polarization of the sugar unhydrolyzed. The remainder was the rotation of the products of hydrolysis. If fructose, the quantity was $5.21 \mathrm{~g}$ per $100 \mathrm{ml}$. During the period of 23 minutes heating 65 per cent of the original carbohydrate was hydrolyzed.

If any product but fructose were produced by hydrolysis, none of the three independent methods of calculation would approximate the total reducing sugar. It is thus evident that the sole product of hydrolysis was fructose. In further confirmation of this conclusion we may calculate roughly the velocity constant of hydrolysis. The initial rotation, +24.44 , was directly observed. The rotatory power at complete hydrolysis may be calculated by multiplying the initial weight of substance by 1.11 (that is, the ratio, $2 \mathrm{C}_{6} \mathrm{H}_{12} \mathrm{O}_{6}$ to $\mathrm{C}_{12} \mathrm{H}_{20} \mathrm{O}_{10}$ ) and converting to saccharimeter degrees on the assumption that fructose is the product of hydrolysis. The velocity constant for 8 minutes

12 B. S. Sci. Paper No. 519, 20, p. 609; 1926. 
proved to be 0.018 and for 23 minutes, 0.020 . If any substance other than fructose were produced, these values could not approach constancy.

\section{DIFRUCTOSE ANHYDRIDE HEXA-ACETATE}

The alcoholic solution containing $3.3 \mathrm{~g}$ of the disaccharide was evaporated in vacuo to a thick sirup and mixed with $40 \mathrm{ml}$ of acetic anhydride, of which $25 \mathrm{ml}$ was distilled off, carrying with it the remainder of the alcohol. To the residue $20 \mathrm{ml}$ of acetic anhydride and $17 \mathrm{ml}$ of pyridine were added and the mixture warmed for a short time to $60^{\circ}$ to $70^{\circ}$ and then left overnight at room temperature. The reaction mixture, poured into a large volume of ice water, separated as an oil which, after washing and neutralization with $\mathrm{NaHCO}_{3}$, became a viscous wax, with no indications of complete hardening. Only after standing for five or six weeks did it harden sufficiently to indicate a partial crystallization. It was then dissolved in alcohol and a portion recovered in the form of prismatic needles; yield, about 30 per cent of the theoretical. Upon purification and analysis this substance proved to be the hexa-acetate of a disaccharide.

In an effort to produce a more highly substituted acetate, the acetylation was repeated with many modifications, of which the following are typical. Whenever possible the course of the reaction was followed by polariscopic observation.

A solution of $3.2 \mathrm{~g}$ of disaccharide in $16 \mathrm{~g}$ of acetic anhydride rotated +50.5 saccharimeter degrees in a $200 \mathrm{~mm}$ tube. One-tenth gram of zinc chloride was added and the mixture allowed to stand overnight at room temperature and then one and one-half hours at $50^{\circ}$. It was found that the rotation of the solution after cooling had risen to $56.4^{\circ}$ and remained at this value after repeated heating and cooling. The reaction mixture was poured into iced water, neutralized with $\mathrm{NaHCO}_{3}$, and extracted with chloroform. The chloroform solution was washed with water, dried with $\mathrm{CaCl}_{2}$, and evaporated to a small volume. The crystalline substance which separated as prismatic needles was the same hexa-acetate as that obtained by catalysis with pyridine; yield, 30 per cent of the theoretical.

Similarly, an acetylation in the presence of sodium acetate produced a mixture of increased dextrorotatory power which yielded the same crystalline acetate.

The pure crystalline hexa-acetate was dissolved in acetic anhydride and an attempt made to acetylate further with zinc chloride as catalyst. The original substance was recovered in unaltered form.

Finally, $1.2 \mathrm{~g}$ of hexa-acetate was dissolved in $10 \mathrm{ml}$ of chloroform and $1 \mathrm{~g} \mathrm{PCl}_{5}$ added in an effort to replace any unsubstituted hydroxyls by halogen. No product but the original hexa-acetate was recovered. 
The acetylated sugar was recrystallized from alcohol to constant melting point and specific rotation. The purified substance in a capillary tube showed a visible sintering at $125^{\circ} \mathrm{C}$. and melted sharply at $137^{\circ} \mathrm{C}$. (uncorrected). Anal. Subs., 0.2569, 0.3242: $\mathrm{CO}_{2}$, 0.4721, 0.5899; $\mathrm{H}_{2} \mathrm{O}, 0.1298,0.1623$. Calcd. for $\mathrm{C}_{12} \mathrm{H}_{14} \mathrm{O}_{10}\left(\mathrm{OCCH}_{3}\right)_{8}$ : $\mathrm{C}, 50.00 ; \mathrm{H}, 5.56$. Found: $\mathrm{C}, 50.12,49.63 ; \mathrm{H}, 5.65,5.60$. Rotation. $[\alpha]_{D}^{20}$ in $\mathrm{CHCl}_{3}=+0.54\left(2.496\right.$ in $25 \mathrm{ml}, \alpha=+0.31^{\circ}$, saccharimeter, 2-dm tube). $[\alpha]_{5780}^{20}=+0.65$ (2.674 in $25 \mathrm{ml}, \alpha=+0.138^{\circ}$, circular), and $[\alpha]_{5461}^{20}=+0.69\left(2.674\right.$ in $\left.25 \mathrm{ml}, \alpha=+0.147^{\circ}\right)$.

For the determination of acetyl groups the acetate was dissolved by heating gently in an excess of $\mathrm{Ba}(\mathrm{OH})_{2}$ solution, and allowed to stand overnight. The excess alkali was titrated with acetic acid (Phenolphthalein). Anal. Subs., 0.2031, 0.2261 required $18.760 \mathrm{~g}$, $20.934 \mathrm{~g}$ of $0.11296 \mathrm{~N} \mathrm{Ba}(\mathrm{OH})_{2}$ (weight burette). Calcd. for $\mathrm{C}_{12} \mathrm{H}_{14} \mathrm{O}_{10}\left(\mathrm{OCCH}_{3}\right)_{6}: \mathrm{OCCH}_{3}, 44.80$. Found: 44.87, 44.97. Mol. wt. Subs., 1.0006, 0.8014: benzene, 23.488, 22.983; $\Delta T, 0.376,0.317^{\circ}$. Calcd: 576. Found: 582, 566.

The mother liquors remaining from the hexa-acetate crystallization have even to the present writing continued to yield further quantities of the hexa-acetate by slow crystallization, but no isomeric acetate has yet crystallized. That they contain an acetylated disaccharide of high rotatory power is indicated by the following experimental data. The dry substance in the solution was determined by drying on sand at $85^{\circ}$. Mol. wt., Subs., 3.102: benzene, 22.074; $\Delta T, 1.256^{\circ}$. Mol. wt., 573. Rotation. $[\alpha]_{D}^{21}$ in $\mathrm{CHCl}_{3}=+31$ (5.60 in $100 \mathrm{ml}, \alpha=+10.03^{\circ}$, saccharimeter, 2 -dm tube).

\section{DIFRUCTOSE ANHYDRIDE I}

Difructose anhydride hexa-acetate was suspended in an excess of $\mathrm{Ba}(\mathrm{OH})_{2}$, warmed gently until completely dissolved and allowed to stand overnight. The calculated volume of $\mathrm{H}_{2} \mathrm{SO}_{4}$ sufficient to remove the barium quantitatively was added and the filtrate evaporated in a vacuum to nearly complete dryness. Absolute alcohol was added and the solution filtered with carbon. The filtered solution was evaporated on the steam bath to a relatively small volume and set aside to crystallize. By the following morning the crystalline sugar appeared in the form of spheres consisting of clusters of minute crystals. In all crystallizations subsequent to the first it was possible to seed the saturated solution and produce an unclustered crystal mass. Well-developed crystals on the microscope slide took the form of thin rectangular plates. The substance was readily purified by crystallization from hot absolute alcohol. Anal. Subs., 0.1540, 0.2232: $\mathrm{CO}_{2}, 0.2491,0.3614 ; \mathrm{H}_{2} \mathrm{O}, 0.0856,0.1227$. Calcd. for $\mathrm{C}_{12} \mathrm{H}_{20} \mathrm{O}_{10}: \mathrm{C}$, $44.42 ; \mathrm{H}, 6.22$. Found: $\mathrm{C}, 44.12,44.16 ; \mathrm{H}, 6.22,6.15$. Rotation. $[\alpha]_{D}^{20}$ in $\mathrm{H}_{2} \mathrm{O}=+26.9$ (2.113 in $25 \mathrm{ml}, \alpha=+13.08^{\circ}$, saccharimeter. 
2 -dm tube); a second solution gave $[\alpha]_{D}^{20}=+27.0(1.024$ in $25 \mathrm{ml}$, $\alpha=+6.39^{\circ}$, saccharimeter $)$, and $[\alpha]_{5780}^{20}=+27.6\left(\alpha=+2.257^{\circ}\right.$, circular $)$, and $[\alpha]_{5461}^{20}=+30.7(\alpha=2.510)$.

\section{HYDROLYSIS OF DIFRUCTOSE ANHYDRIDE I}

A $25.0 \mathrm{ml}$ solution containing $78.8 \mathrm{mg}$ difructose anhydride and sufficient $\mathrm{H}_{2} \mathrm{SO}_{4}$ to make $0.20 \mathrm{~N}$ was heated at $100^{\circ} \mathrm{C}$. for 100 minutes. Upon analysis it was found to contain $2.95 \mathrm{mg}$ of total reducing sugar and $2.80 \mathrm{mg}$ of fructose per milliliter. The essential agreement indicates that fructose is the only product of hydrolysis.

The original disaccharide would yield, if hydrolysis were complete, $3.50 \mathrm{mg}$ of reducing sugar per milliliter (that is, $78.8 \times 1.11 \div 25$ ), while actually in a period of 100 minutes $\frac{2.95}{3.50}=84.3$ per cent of the disaccharide was hydrolyzed. The velocity of reaction can be roughly calculated for the conditions specified.

$$
k=\frac{1}{100} \log \frac{100}{100-84.3}=0.008
$$

in terms of minutes and common logarithms. $\quad\left(0.2 \mathrm{~N} \mathrm{H}_{2} \mathrm{SO}_{4}\right.$ and $T=100^{\circ}$ C.)

A $25 \mathrm{ml}$ solution containing $7.8 \mathrm{mg}$ of difructose anhydride and 0.2 $\mathrm{N} \mathrm{H}_{2} \mathrm{SO}_{4}$ was heated at $100^{\circ}$. One-milliliter samples were withdrawn at various intervals of time and analyzed by the method of Folin and $\mathrm{Wu} .^{13}$ The mean value of the velocity constant for three intervals of time was 0.0083 . A quinhydrone electrode in the solution coupled with a saturated calomel half cell showed a potential of $0.395 v, t=27^{\circ}$; whence $\mathrm{pH}=0.965$ and $\mathrm{C}_{\mathrm{H}}=0.109$.

In a previous section we have shown that the velocity of hydrolysis of the mixture of disaccharides in the presence of $0.4 \mathrm{~N} \mathrm{H}_{2} \mathrm{SO}_{4}$ at $100^{\circ}$ C. was 0.019 . In $0.2 N$ acid this would be approximately 0.010 .

The mean of these three estimates of the velocity constant is 0.009 , which value is employed for the purpose of comparing the stability of difructose anhydride I with the remainder of the inulin molecule.

\section{EFFECT OF $\mathrm{H}_{2} \mathrm{SO}_{4}$ ON PURE FRUCTOSE}

An aqueous solution containing approximately 14 per cent of fructose was made $0.0732 \mathrm{~N}$ with $\mathrm{H}_{2} \mathrm{SO}_{4}$ and divided into two portions. One portion was retained for a standard of comparison; the other was heated at $48.6^{\circ} \mathrm{C}$. for four hours. The rotations of the control and heated solutions were, respectively, $-75.27^{\circ}$ and $-75.20^{\circ}$ (saccharimeter). The apparent loss of purity was, therefore, 0.10 per cent. The oxidizability by iodine increased 0.08 per cent estimated

13 J. Biol. Chem.,38, p. 81; 1919; 41, p. 367; 1920 . 
as glucose. There was, therefore, no condensation of fructose under these conditions.

An 11.5 per cent fructose solution $0.005 N$ with respect to the first hydrogen of tartaric acid was heated two and one-half hours at $100^{\circ}$. The sugar suffered a loss of 0.5 per cent in purity and an increase in 0.3 per cent reactivity with iodine.

\section{SUMMARY}

Inulin upon hydrolysis with dilute acid yields solutions containing in 100 per cent solid matter 91.8 per cent fructose, 94.8 per cent reducing sugar, and a 5.2 per cont unfermentable residue.

The residue has a $[\alpha]_{D}^{20}=+55$ and is hydrolyzed by $0.4 \mathrm{~N} \mathrm{H}_{2} \mathrm{SO}_{4}$ at $100^{\circ} \mathrm{C}$. solely to fructose. It is twenty-five times as resistant to hydrolysis as the remainder of the inulin molecule.

Acetylation of the original residue yielded a mixture of acetates, one of which crystallized in 30 per cent yield in the form of prismatic ncedles of $[\alpha]_{D}^{20}=+0.54$. This was found to be the hexa-acetate of a disaccharide containing but six hydroxyl groups.

The mother liquors from the crystalline acetate contained one or more acetylated difructoses with a mean $[\alpha]_{D}^{20}=+31$.

The crystalline hexa-acetate upon deacetylation yielded a crystalline difructose anhydride of $[\alpha]_{D}^{20}=+27$. The latter was hydrolyzed to fructose by $0.2 \mathrm{~N} \mathrm{H}_{2} \mathrm{SO}_{4}$ at $100^{\circ} \mathrm{C}$. with a velocity constant of 0.009 (common logarithms, minutes).

The original residue of $[\alpha]_{D}^{20}=+55$ contains additional difructoses which have not as yet been isolated.

Washington, January 5, 1929. 